\title{
Tobacco curly shoot virus DNA $\beta$ Is Not Necessary for Infection but Intensifies Symptoms in a Host-Dependent Manner
}

\author{
Zhenghe Li, Yan Xie, and Xueping Zhou
}

Institute of Biotechnology, Zhejiang University, Hangzhou 310029, P.R. China.

Accepted for publication 7 April 2005.

\begin{abstract}
Li, Z., Xie, Y., and Zhou, X. 2005. Tobacco curly shoot virus DNA $\beta$ is not necessary for infection but intensifies symptoms in a host-dependent manner. Phytopathology 95:902-908.

We demonstrated that only 11 isolates were associated with DNA $\beta$ among 39 Tobacco curly shoot virus (TbCSV)-infected, field-collected samples. An infectious clone of TbCSV-[Y35], an isolate associated with DNA $\beta$, induced severe upward leaf curling in Nicotiana benthamiana. In the presence of its cognate DNA $\beta$ (TbCSV-[Y35] DNA $\beta$ ), the symptom changed to a downward leaf curl. Furthermore, TbCSV-[Y35] alone was able to induce severe symptoms in tobacco and tomato plants, although co-infection with DNA $\beta$ intensified symptom severity in tobacco plants. In contrast to other begomovirus-DNA $\beta$ complexes, the satellite had no effect on the accumulation of TbCSV-[Y35] DNA in systemically in-

fected host plants. The $\beta C 1$ mutant caused symptoms comparable to those induced by TbCSV-[Y35] in the absence of DNA $\beta$. TbCSV-[Y35] can be transmitted between plants by a whitefly vector, regardless of the presence or absence of DNA $\beta$. For a TbCSV isolate not associated with DNA $\beta$ (TbCSV-[Y1]), systemic infection of $N$. benthamiana induced symptoms resembling those of TbCSV-[Y35]. Co-infection of TbCSV[Y1] with TbCSV-[Y35] DNA $\beta$ induced symptoms similar to those following infection by TbCSV-[Y35] and its DNA $\beta$. This indicates that TbCSV DNA $\beta$ is not necessary for infection but intensifies symptoms in a host-dependent manner. Thus, TbCSV may represent an evolutionary intermediate between the DNA $\beta$ requiring begomoviruses and the truly monopartite begomoviruses. The relevance of these results to our present understanding of the evolution of begomovirus-satellite disease complexes is discussed.
\end{abstract}

Geminiviruses are single-stranded DNA containing plant viruses with geminate particle morphology (16). Taxonomically they have been divided into four genera (Mastrevirus, Curtovirus, Topocuvirus, and Begomovirus) based on insect vector, host range, and genome structure (31). Most geminiviruses belong to the genus Begomovirus, which are transmitted exclusively by the whitefly Bemisia tabaci and infect only dicotyledonous plants. The majority of begomoviruses have genomes consisting of two genomic components designated as DNA-A and DNA-B, each approximately $2.7 \mathrm{~kb}$ in size. DNA-A encodes genes responsible for virus replication, regulation of gene expression, and encapsidation, whereas DNA-B component encodes two proteins involved in efficient systemic spread in hosts and symptom modulation (11). A small number of begomoviruses, such as Tomato yellow leaf curl virus (TYLCV) (21) and Tomato leaf curl virus (ToLCV) (9), have a single genomic component homologous to DNA-A. These monopartite begomoviruses do not require the functions encoded by DNA-B, employing a mechanistically distinct movement strategy $(10,24)$.

Recently, some monopartite begomoviruses including Ageratum yellow vein virus (AYVV) and Cotton leaf curl Multan virus (CLCuMV) have been shown to be associated with a novel singlestranded DNA satellite, termed DNA $\beta(5,12,19,25,28)$. In the absence of DNA $\beta$, these viruses are either not infectious or poorly infectious to their natural hosts and accumulate to significantly lower levels than those observed in naturally infected plants. DNA $\beta$ is required for induction of bona fide disease symptoms and amplification of the virus to wild-type levels in systemically infected tissues. The precise function of DNA $\beta$ in pathogenesis is

Corresponding author: X. Zhou; E-mail address: zzhou @zju.edu.cn

DOI: 10.1094/PHYTO-95-0902

(C) 2005 The American Phytopathological Society unknown, although it has been suggested that DNA $\beta$ may be involved in either enhancing replication, facilitating movement, or countering a host defense mechanism (25). Recently, the single gene $(\beta \mathrm{C} 1)$ encoded by DNA $\beta$ of AYVV or Tomato yellow leaf curl China virus (TYLCCNV) has been shown to be an essential pathogenicity determinant $(7,29)$.

Tobacco curly shoot virus (TbCSV) occurs in Yunnan, China and infects mainly Oriental tobacco (Nicotiana tabacum cv. Samsun) and tomato (Lycopersicon esculentum) $(17,33 ; \mathrm{X}$. Zhou, unpublished data). We have previously shown the virus to be a monopartite begomovirus that is associated with a DNA $\beta$ satellite (34). In the present work, we demonstrated that only some TbCSV isolates contain DNA $\beta$. In addition, we show that TbCSV is able to induce severe disease symptoms and accumulate to high levels in plants in the absence of DNA $\beta$.

\section{MATERIALS AND METHODS}

Origins of virus isolates and DNA extraction. Between 1999 and 2004, 185 field-infected N. tabacum and L. esculentum plants, showing begomovirus-like symptoms, were collected in fields located in different districts of Yunnan Province, China. Total nucleic acids were extracted from field-collected leaf samples as described in Xie et al. (33).

Detection of TbCSV and TbCSV DNA $\beta$. Primers specific for the polymerase chain reaction (PCR)-mediated detection of TbCSV and TbCSV DNA $\beta$ were designed based on the previously published sequences of these components $(33,34)$. The TbCSVspecific primers (TbCSVF, 5'-CGTAGGCCTGTGGATAAACCTCAAGAT-3'; Y6R2， 5'-GGAAGCCAGTTCAAATTAAAGG-3') and TbCSV DNA $\beta$-specific primers (TbCSV $\beta 1,5^{\prime}$-CGTAGGCCTGTGGATAAACCTCAAGAT-3'; Beta02, 5'-AGTGGTACCTACCCTCCCAGGGGTACAC-3') were designed to amplify fragments approximately 1.3 and $1.2 \mathrm{~kb}$ in size, respectively. These primers were used in PCR analysis using standard protocols. 
Clone construction and plant inoculation. A full-length clone of TbCSV was produced from isolate Y35 by PCR amplification using primers Y35F (5'-CTGGATCCATTAGTAAACGAGTTTC$\left.3^{\prime}\right)$ and Y35R (5'-TAGGATCCCACATAGTGCGGAGTGC-3') that overlap at a unique BamHI site (underlined) and were based on the sequence of TbCSV-[Y35] (AJ420318). A full-length copy of the genome was amplified using these primers and cloned into the pGEM-T vector (Promega, Madison, WI) yielding pGEMTbCSV-Y35. After confirmation by sequencing with the automated DNA sequencing system (Model 377; Perkins Elmer, Wellesley, MA), an approximate 2,680-bp BamHI-HindIII digested fragment of pGEMTbCSV-Y35, encompassing the intergenic region, was subcloned into the binary vector pBinPLUS (32) to produce clone pBinY35A-0.9. Then the full-length BamHI-digested fragment of pGEMTbCSV-Y35 was inserted into the unique BamHI restriction site of pBinY35A-0.9 to produce clone pBinY35A-1.9. Partial dimeric construct of TbCSV-[Y1] (pBinY1A-1.9) for agroinoculation was produced by an identical strategy using primers $\mathrm{Y} 35 \mathrm{~F}$ and $\mathrm{Y} 35 \mathrm{R}$, which are conserved between TbCSV-[Y1] and TbCSV-[Y35]. Dimeric constructs of TbCSV-[Y2] and TbCSV-[Y35] DNA $\beta$ clones for agroinoculation, pBinY $2 \beta-2.0$ and $\mathrm{pBinY} 35 \beta-2.0$, were produced using the same method described previously (34). These binary vectors carrying viral or DNA $\beta$ constructs were introduced into Agrobacterium tumefaciens strain EHA105 by direct transformation or by triparental mating.

Construction of a $\beta C 1$ mutant of TbCSV-[Y35] DNA $\beta$. The plasmid pGEMY35 $\beta$-1.0 containing the full-length genome of TbCSV-[Y35] DNA $\beta$ amplified with universal primer pair Beta01/Beta02 (3) was used as template for mutagenesis of $\beta C 1$. A pair of overlapping primers (C1mF, 5'-GTTGTATTTAATTcaCATATTTGTTC-3'; C1mR, 5'-GAACAAATATGtgAATTAAATACAAC-3'; nucleotide changes shown in lower case) was designed to introduce a premature termination codon (TGA) immediately following the initiation codon (ATG) of $\beta C 1$ open reading frame $(\mathrm{ORF})$. The introduced nucleotide changes do not alter the amino acid sequence of the putative virion-sense ORF. The mutant clone pGEMY35 $\beta \mathrm{C} 1 \mathrm{~m}-1.0$ was produced by overlapextension PCR using the flanking primers Beta01 and Beta02, and products were cloned into pGEM-T Easy (Promega). A dimeric construct of this clone was produced in pBinPLUS and transferred to A. tumefaciens as described previously (34).

Agroinoculation of plants. A. tumefaciens cultures harboring dimeric or partial dimeric constructs in binary vectors were grown at $28^{\circ} \mathrm{C}$ for $48 \mathrm{~h}$. For co-inoculation of TbCSV and DNA $\beta$, equal volumes of the separate bacterial cultures were mixed prior to inoculation. A 21-gauge needle was used to inject $0.2 \mathrm{ml}$ of bacterial culture into stems or petioles of plants at the four- to sixleaf stage. Inoculated plants were grown in an insect-free cabinet with supplementary lighting to give a 16-h day length and were checked daily for the appearance of symptoms.

Analysis of inoculated plants. Total nucleic acids were isolated from young leaves of $N$. benthamiana, tobacco, and tomato plants using the CTAB method (35). Nucleic acids were run on $1 \%$ agarose gel in TBE buffer ( $90 \mathrm{mM}$ Tris-borate, $2 \mathrm{mM}$ EDTA, $\mathrm{pH}$ 8.3) and transferred to Hybond-N+ membranes (Amersham Biosciences, Buckinghamshire, England) by capillary blotting. Membranes were hybridized to $\left[\alpha^{32} \mathrm{P}\right] \mathrm{dCTP}$-labeled probes specific for TbCSV-[Y1], TbCSV-[Y35], or TbCSV DNA $\beta$. The virusspecific probes were produced by labeling $B a m \mathrm{HI}-S p h \mathrm{I}$ restriction fragments of the respective viruses, and the DNA $\beta$ probe was produced by labeling an equi-molar mixture of the full-length KpnI inserts of TbCSV-[Y2] DNA $\beta$ and TbCSV-[Y35] DNA $\beta$.

Whitefly transmission assay. B. tabaci were fed on infected N. tabacum cv. Samsun plants in closed cages within an insectfree cabinet with supplementary lighting to give a 12-h day length. Inoculation was achieved by transferring viruliferous insects to five healthy tobacco plants for a minimum 48-h transmission access period. Following inoculation, insects were removed and plants were fumigated twice weekly with insecticide and maintained in an insect-free cabinet. Plants were checked daily for the appearance of symptoms.

\section{RESULTS}

DNA $\beta$ is not associated with all TbCSV isolates. Previously, we have characterized three tobacco-infecting (Y1, Y2, and Y35) and one tomato-infecting (Y41) isolates of TbCSV $(33,34)$. PCRmediated amplification with a pair of universal primers Beta01/ Beta02 (3) showed DNA $\beta$ to be associated with isolates Y2 and Y35, but not with isolates Y1 and Y41. An additional 181 tobacco and tomato samples with begomovirus-like symptoms collected from Yunnan Province were tested by triple-antibody sandwich, enzyme-linked immunosorbent assay with a panel of monoclonal antibodies raised against begomoviruses, and 35 of the samples gave a reaction pattern typical of previously characterized TbCSV isolates (data not shown). In addition, PCR analysis using primers specific for TbCSV yielded a diagnostic 1.3-kb fragment, confirming the presence of TbCSV in these samples (Table 1). However, only nine samples yielded a diagnostic product with primers TbCSV $\beta 01$ and Beta02 specific for TbCSV DNA $\beta$ (Table 1). For

TABLE 1. Polymerase chain reaction-mediated detection of Tobacco curly shoot virus (TbCSV) and DNA $\beta$ in naturally infected plants collected from Yunnan province

\begin{tabular}{|c|c|c|c|c|c|}
\hline \multirow{2}{*}{$\begin{array}{l}\text { Sample } \\
\text { no. }\end{array}$} & \multirow[b]{2}{*}{ Year } & \multirow{2}{*}{$\begin{array}{c}\text { Plant } \\
\text { species }\end{array}$} & \multirow[b]{2}{*}{ Symptoms ${ }^{\mathrm{a}}$} & \multicolumn{2}{|c|}{ Presence of } \\
\hline & & & & TbCSV & TbCSV DNA $\beta$ \\
\hline Y1 & 1999 & Tobacco & $\mathrm{CS}, \mathrm{VT}, \mathrm{LC}, \mathrm{ST}$ & + & - \\
\hline $\mathrm{Y} 2$ & 1999 & Tobacco & $\mathrm{CS}, \mathrm{VT}, \mathrm{LC}, \mathrm{ST}$ & + & + \\
\hline Y35 & 2001 & Tobacco & $\mathrm{LC}$ & + & + \\
\hline Y41 & 2001 & Tomato & $\mathrm{LC}$ & + & - \\
\hline Y87 & 2002 & Tobacco & $\mathrm{CS}, \mathrm{EN}$ & + & - \\
\hline Y88 & 2002 & Tobacco & $\mathrm{CS}, \mathrm{EN}$ & + & - \\
\hline Y92 & 2002 & Tobacco & $\mathrm{CS}, \mathrm{LC}, \mathrm{VT}$ & + & - \\
\hline Y93 & 2002 & Tobacco & $\mathrm{CS}, \mathrm{LC}, \mathrm{VT}$ & + & - \\
\hline Y98 & 2002 & Tobacco & $\mathrm{CS}$ & + & + \\
\hline Y99 & 2002 & Tobacco & $\mathrm{CS}$ & + & - \\
\hline Y107 & 2002 & Tobacco & LC, ST, VD & + & - \\
\hline Y108 & 2002 & Tobacco & LC, ST, VD & + & - \\
\hline Y111 & 2002 & Tobacco & LC, ST, VD & + & - \\
\hline Y112 & 2002 & Tobacco & LC, ST, VD & + & - \\
\hline Y115 & 2002 & Tobacco & LC, ST, VD & + & + \\
\hline Y117 & 2002 & Tobacco & $\mathrm{LC}, \mathrm{ST}, \mathrm{VD}$ & + & - \\
\hline Y121 & 2002 & Tobacco & $\mathrm{LC}, \mathrm{VT}$ & + & - \\
\hline Y122 & 2002 & Tobacco & LC, VT & + & - \\
\hline Y124 & 2002 & Tobacco & $\mathrm{CS}, \mathrm{ST}$ & + & - \\
\hline Y127 & 2002 & Tobacco & $\mathrm{CS}, \mathrm{ST}$ & + & - \\
\hline Y128 & 2002 & Tobacco & $\mathrm{CS}, \mathrm{ST}$ & + & + \\
\hline Y130 & 2002 & Tobacco & $\mathrm{CS}, \mathrm{ST}$ & + & - \\
\hline Y132 & 2002 & Tobacco & $\mathrm{CS}, \mathrm{ST}$ & + & - \\
\hline Y134 & 2002 & Tobacco & LC, VT & + & + \\
\hline Y135 & 2002 & Tobacco & LC, VT & + & - \\
\hline Y137 & 2002 & Tobacco & LC, VT & + & + \\
\hline Y141 & 2002 & Tobacco & $\mathrm{LC}$ & + & + \\
\hline Y142 & 2002 & Tobacco & $\mathrm{LC}$ & + & - \\
\hline Y144 & 2002 & Tobacco & $\mathrm{LC}$ & + & + \\
\hline Y145 & 2003 & Tobacco & $\mathrm{CS}, \mathrm{VT}$ & + & + \\
\hline Y146 & 2003 & Tobacco & $\mathrm{CS}, \mathrm{VT}$ & + & - \\
\hline Y147 & 2003 & Tobacco & $\mathrm{CS}, \mathrm{VT}$ & + & - \\
\hline Y148 & 2003 & Tobacco & $\mathrm{CS}, \mathrm{VT}$ & + & - \\
\hline Y151 & 2003 & Tobacco & $\mathrm{CS}, \mathrm{VT}$ & + & + \\
\hline Y152 & 2003 & Tobacco & CS, VT, LC & + & - \\
\hline Y157 & 2003 & Tobacco & $\mathrm{CS}, \mathrm{VT}, \mathrm{LC}, \mathrm{VT}$ & + & - \\
\hline Y158 & 2003 & Tobacco & $\mathrm{CS}, \mathrm{VT}, \mathrm{LC}, \mathrm{VT}$ & + & - \\
\hline Y163 & 2003 & Tomato & LC, ST, VT & + & - \\
\hline Y207 & 2003 & Tomato & YLC & + & - \\
\hline
\end{tabular}

${ }^{a} \mathrm{CS}$, curly shoot; EN, enation; LC, leaf curl; ST, stunt; VD, vein darkening; VT, vein thickening; and YLC, yellow leaf curl. All samples, except Y41, were collected from Baoshen district of Yunnan province (Y41 was collected from Dehong district). 
those without diagnostic product with primers TbCSV $\beta 01$ and Beta02, the universal DNA $\beta$ primer pair Beta01/Beta02 failed to amplify a product in most of them with the exception of isolates Y87, Y88, Y92, and Y142, indicating that some TbCSV isolates are not associated with DNA $\beta$. For isolates Y87, Y88, Y92, and Y142, amplification with primers specific for TYLCCNV and its cognate DNA $\beta$ did produce a diagnostic product (data not shown); these isolates are thus co-infections of TYLCCNV and its cognate DNA $\beta$ with TbCSV.

The presence of DNA $\beta$ was confirmed by Southern blot analysis. Previously, we have shown that DNA $\beta$ molecules associated with TbCSV have more than $83 \%$ nucleotide sequence identity and have an identical stretch of approximately 115 nucleotides, a sequence known as the satellite conserved region (SCR) (34). A probe of the SCR would thus be expected to detect the presence of putative satellite from all TbCSV-infected samples under intermediate stringency washing conditions (1\% SSC [1× SSC is $0.15 \mathrm{M} \mathrm{NaCl}$ plus $0.015 \mathrm{M}$ sodium citrate] and $0.1 \%$ sodium dodecyl sulfate at $55^{\circ} \mathrm{C}$ for $30 \mathrm{~min}$ ). Confirming the PCR results, an SCR probe hybridized to the selected PCR-positive samples but not to the selected PCR-negative samples (Fig. 1). Higher levels of DNA $\beta$ were detected in isolate Y115 (Fig. 1, lane 7), a sample co-infected with TYLCCNV and its DNA $\beta$ probably due to cross-hybridization to TYLCCNV DNA $\beta$.

Infectivity and symptoms. TbCSV-[Y35] has a genome organization typical of other begomoviruses originating from the Old World (accession no. AJ420318). The clone has 94\% nucleotide sequence identity with TbCSV-[Y1] (33), whereas the satellite associated with strain Y35 (accession no. AJ421484) has between 83 and $98 \%$ nucleotide sequence identity to DNA $\beta$ molecules associated with other isolates of TbCSV (34).

By Agrobacterium-mediated inoculation to $N$. benthamiana, TbCSV-[Y35] was found to be highly infectious (55 plants infected out of 58 inoculated) and induced severe upward leaf curling, vein swelling as well as stunting symptoms. Co-inoculation of TbCSV-[Y35] with TbCSV-[Y35] DNA $\beta$ produced a more severe downward curling of leaves, with upward leaf curling of the older infected leaves in the later stages (Fig. 2A). For

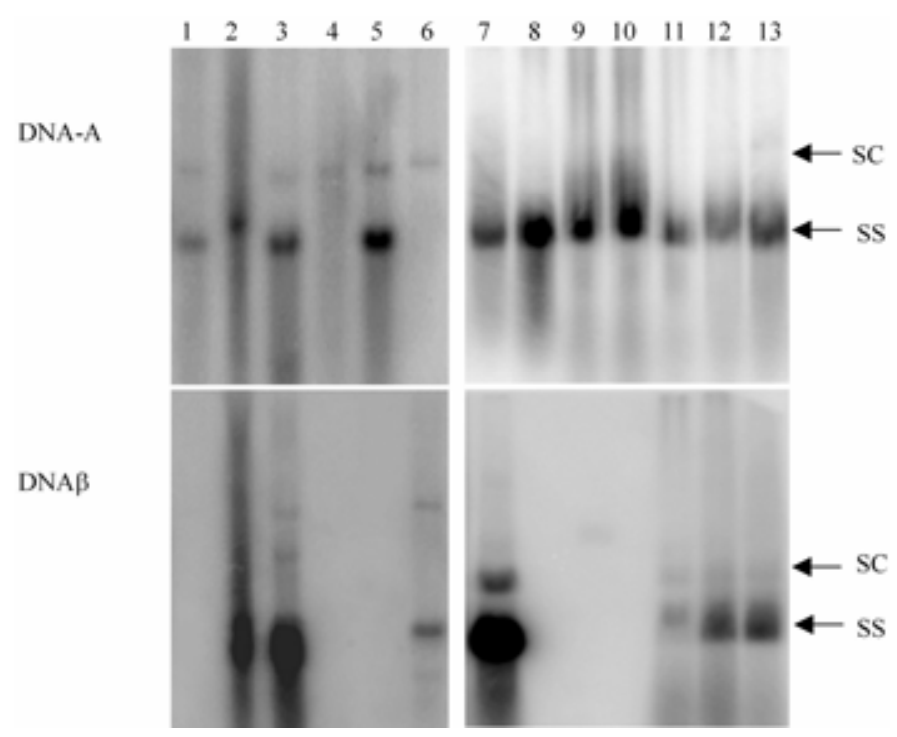

Fig. 1. Detection of viral DNAs in field-collected plant samples infected with Tobacco curly shoot virus (TbCSV). DNA samples were extracted from symptomatic tobacco (lanes 1 to 3 and 5 to 13) and tomato (lane 4) plants collected from Yunnan province. Total nucleic acids $(10 \mu \mathrm{g})$ electrophoresed in lanes 1 to 13 were extracted from isolates Y1, Y2, Y35, Y41, Y93, Y98, Y115, Y117, Y130, Y132, Y137, Y141, and Y144, respectively (Table 1). Blots were hybridized to either TbCSV (DNA-A) or TbCSV DNA $\beta$ (DNA $\beta$ ) probes. The positions of single-stranded (SS) and supercoiled (SC) DNA forms are indicated. infections of $N$. glutinosa with TbCSV-[Y35], the first symptoms developed at 7 days postinoculation (dpi), consisting of downward leaf curling. After several days, previously curling leaves expanded, becoming erect, and the newly emerging leaves showed downward curling (Fig. 2B). N. glutinosa co-infected with TbCSV[Y35] and DNA $\beta$, in contrast, developed severe downward leaf curling and the older infected leaves no longer expanded. In $N$. tabacum cv. Samsun, TbCSV-[Y35] alone was able to efficiently cause a systemic infection (32 plants infected of 32 inoculated) producing symptoms consisting of a mild downward curling of newly emerging leaves, puckering of leaves, and vein thickening. In the presence of DNA $\beta$, the symptom remained the same but was more severe (Table 2). In contrast to Nicotiana spp., infections of tomato with TbCSV-[Y35] induced the same symptoms irrespective of whether DNA $\beta$ was present or not (Table 2). For 6 of 32 tomato plants inoculated with TbCSV-[Y35] and TbCSV DNA $\beta$, only replication of the helper virus could be detected when analyzed by PCR. This indicates that there is little selection pressure for the maintenance of the satellite in this host. Agroinoculation of other plant species indicated that N. tabacum, N. tabacum cv. Xanthi-NC, and Petunia hybrida are hosts of TbCSV-[Y35], whereas Capsicum annuum and Phaseolus vulgaris are not, irrespective of whether DNA $\beta$ is present or not (Table 2).

Systemic infections of plants with TbCSV-[Y35] and TbCSV[Y2] DNA $\beta$ induced qualitatively similar but slightly milder symptoms compared with those induced by TbCSV-[Y35] with its cognate DNA $\beta$ in all host species (Table 2).

TbCSV-[Y1] is able to systemically infect $N$. benthamiana, inducing symptoms qualitatively similar to those induced by TbCSV-[Y35]. When co-inoculated with TbCSV-[Y2] DNA $\beta$ or TbCSV-[Y35] DNA $\beta$, the symptom changed from an upward to a downward curl. The symptoms induced by co-infection with TbCSV-[Y2] DNA $\beta$ were slightly milder than those with TbCSV[Y35] DNA $\beta$ (Fig. 2C).

Analysis of TbCSV and DNA $\beta$ in inoculated plants. Southern blot analysis of $N$. benthamiana, $N$. tabacum, and tomato plants infected by agroinoculation with TbCSV and DNA $\beta$ revealed predominantly single-strand DNA with, in some cases, relatively low levels of supercoiled and subgenomic, doublestranded DNA (Fig. 3). In N. benthamiana plants co-inoculated with TbCSV-[Y35] and either TbCSV-[Y35] DNA $\beta$ or TbCSV[Y2] DNA $\beta$, high levels of the satellites were detected in systemically infected tissue, indicating efficient trans-replication and systemic movement (Fig. 3, lanes 3 to 6). The levels of TbCSV[Y35] in systemically infected $N$. benthamiana were similar irrespective of whether DNA $\beta$ was present or not (Fig. 3, lanes 1 to 6). Southern blot analysis of tobacco plants showed TbCSV-[Y35] is able to spread systemically and accumulate to high levels in the absence of DNA $\beta$ (Fig. 3, lanes 9 to 11), and the levels of viral DNA remained largely unaffected by the presence of either TbCSV-[Y35] DNA $\beta$ or TbCSV-[Y2] DNA $\beta$ (Fig. 3, lanes 12 to 17). Similarly, viral DNA levels were unaffected by the presence of DNA $\beta$ in systemically infected tomato tissues (Fig. 3, lanes 20 to 28), although the relative levels of the satellite in these plants were more variable than those in systemically infected $N$. benthamiana and N. tabacum (Fig. 3, lanes 23 to 28). Southern blot analysis further confirmed that only the helper virus could be replicated in some tomato plants co-inoculated with TbCSV-[Y35] and TbCSV-[Y35] DNA $\beta$ (Fig. 3, lane 24). These findings demonstrate that, in contrast to AYVV and CLCuMV $(5,25)$, DNA $\beta$ has no significant effect on the accumulation of viral DNA for TbCSV. Additionally, no correlation between symptom severity and the level of TbCSV was evident. Similarly, Southern blot analysis showed that TbCSV-[Y1] is able to systemically infect and accumulate to high levels in $N$. benthamiana (Fig. 4, lane 1). Furthermore, replication of DNA $\beta$ was detected in systemically infected $N$. benthamiana plants co-inoculated with TbCSV-[Y1] 
and either TbCSV-[Y2] DNA $\beta$ or TbCSV-[Y35] DNA $\beta$ (Fig. 4, lanes 5 and 6). This confirms that TbCSV-[Y1], a virus not associated with a satellite in the field, has the capacity to functionally interact with TbCSV DNA $\beta$.
Whitefly transmission of progeny virus. Whiteflies were used to transmit progeny virions from individual symptomatic plants that had been agroinoculated with TbCSV-[Y35] or with TbCSV-[Y35] and DNA $\beta$ to healthy $N$. tabacum test seedlings.

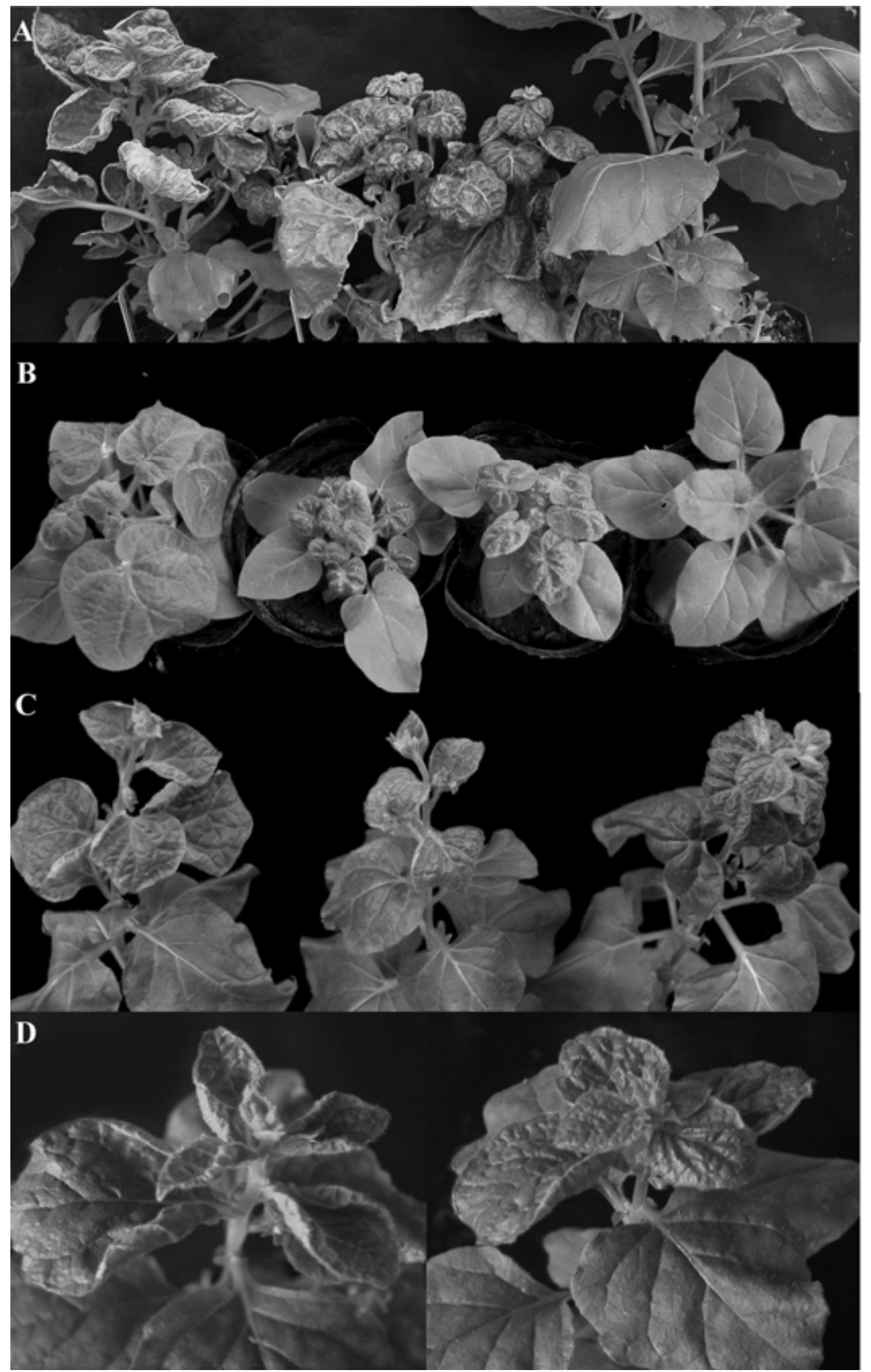

Fig. 2. Symptoms induced by Tobacco curly shoot virus (TbCSV). A, Nicotiana benthamiana photographed at 38 days postinoculation; from left to right, plants were infected with TbCSV-[Y35], TbCSV-[Y35] with TbCSV-[Y35] DNA $\beta$, TbCSV-[Y35] with TbCSV-[Y2] DNA $\beta$, or uninfected. B, TbCSV-[Y35] infection of $N$. glutinosa at 31 days postinoculation; order of plants as in A. C, Symptoms induced by TbCSV-[Y1] (left), TbCSV-[Y1] with either TbCSV-[Y2] DNA $\beta$ (center), or TbCSV-[Y35] DNA $\beta$ (right) in $N$. benthamiana at 31 days postinoculation. D, $N$. benthamiana plants infected with TbCSV-[Y35] (left) or TbCSV[Y35] with the DNA $\beta \mathrm{C} 1$ mutant (right) at 42 days postinoculation. 
Typical systemic disease symptoms, indistinguishable from those of the agroinoculated source plants, developed in the test plants (data not shown). The accumulation of TbCSV-[Y35] and DNA $\beta$ in recipient plants was verified by Southern blot hybridization (Fig. 3, lanes 18 and 19). These results demonstrate that TbCSV[Y35] can be transmitted between plants by whitefly vector, regardless of the presence or absence of DNA $\beta$.

Mutagenesis of TbCSV-[Y35] DNA $\beta$. The $\beta C 1$ mutant was agroinoculated to $N$. benthamiana in the presence of TbCSV[Y35]. Systemic leaf curling symptoms developed approximately 7 dpi. The symptoms were comparable to those induced by TbCSV-[Y35] in the absence of DNA $\beta$, although the curling of leaf margins was less pronounced (Fig. 2D). However, these symptoms were clearly distinct from the severe downward leaf curling induced by TbCSV-[Y35] in the presence of DNA $\beta$ in this host (Fig. 2A). Southern blot analysis showed that the mutant retained the capacity to be trans-replicated and systemically spread by its helper virus in this host (Fig. 3, lanes 7 and 8).

\section{DISCUSSION}

Since the discovery of DNA $\beta$ associated with AYVV from Singapore and CLCuMV from Pakistan $(5,25)$, an increasing number of such satellites have been found in association with begomoviruses infecting diverse plant species $(1,6,34)$. To date, all characterized begomoviruses associated with DNA $\beta$ are monopartite and occur in the Old World. In Yunnan Province of China, a number of monopartite begomoviruses have been found to infect tobacco, tomato, and weeds, of which some are consistently associated with DNA $\beta$ and are unable to induce typical disease symptoms in the absence of the satellite (34). Here, we have demonstrated that only a small proportion of TbCSV isolates are associated with a DNA $\beta$. For AYVV and CLCuMV, DNA $\beta$ is essential for symptom induction in A. conyzoides and cotton, respectively, from which they were isolated $(5,25,26)$. In the absence of the satellite, these viruses are poorly infectious to these hosts and induce either no symptoms or mild atypical symp-

TABLE 2. Infectivity and symptoms induced by Tobacco curly shoot virus (TbCSV)-[Y35] in the presence or absence of DNA $\beta$

\begin{tabular}{|c|c|c|c|c|}
\hline Plants species & Inoculum $^{\mathrm{a}}$ & Infectivity & Onset of symptoms ${ }^{b}$ & Symptoms \\
\hline \multirow{3}{*}{ Nicotiana benthamiana } & Y35A & $55 / 58$ & 7 dpi & Upward leaf curling, vein thickening, and stunt \\
\hline & $\mathrm{Y} 35 \mathrm{~A}+\mathrm{Y} 35 \beta$ & $59 / 61$ & 7 dpi & Downward leaf curling, vein thickening, and stunt \\
\hline & $\mathrm{Y} 35 \mathrm{~A}+\mathrm{Y} 2 \beta$ & $60 / 62$ & 7 dpi & Downward leaf curling, vein thickening, and stunt \\
\hline \multirow[t]{3}{*}{ N. glutinosa } & Y35A & $36 / 36$ & 7 dpi & Mild downward leaf curling, stunt, and vein thickening \\
\hline & $\mathrm{Y} 35 \mathrm{~A}+\mathrm{Y} 35 \beta$ & $36 / 36$ & 7 dpi & Severe downward leaf curling, stunt, and vein thickening \\
\hline & $Y 35 A+Y 2 \beta$ & $36 / 36$ & 7 dpi & Severe downward leaf curling, stunt, and vein thickening \\
\hline \multirow[t]{3}{*}{ N. tabacum Samsun NN or nn } & Y35A & $32 / 32$ & 7 dpi & Mild downward leaf curling, leaf puckering, and vein thickening \\
\hline & $\mathrm{Y} 35 \mathrm{~A}+\mathrm{Y} 35 \beta$ & $32 / 32$ & 7 dpi & Severe downward leaf curling, leaf puckering, and vein thickening \\
\hline & $\mathrm{Y} 35 \mathrm{~A}+\mathrm{Y} 2 \beta$ & $32 / 32$ & 7 dpi & Severe downward leaf curling, leaf puckering, and vein thickening \\
\hline \multirow[t]{3}{*}{ Lycopersicon esculentum } & Y35A & $30 / 32$ & $2-3$ wpi & Leaf curling and crumpling and stunt \\
\hline & $\mathrm{Y} 35 \mathrm{~A}+\mathrm{Y} 35 \beta$ & $31 / 32$ & $2-3$ wpi & Leaf curling and crumpling and stunt \\
\hline & $\mathrm{Y} 35 \mathrm{~A}+\mathrm{Y} 2 \beta$ & $30 / 32$ & $2-3$ wpi & Leaf curling and crumpling and stunt \\
\hline \multirow[t]{3}{*}{ Petunia hybrida } & Y35A & $8 / 8$ & 7 dpi & Upward leaf curling \\
\hline & $\mathrm{Y} 35 \mathrm{~A}+\mathrm{Y} 35 \beta$ & $8 / 8$ & 7 dpi & Downward leaf curling \\
\hline & $\mathrm{Y} 35 \mathrm{~A}+\mathrm{Y} 2 \beta$ & $8 / 8$ & 7 dpi & Downward leaf curling \\
\hline
\end{tabular}

a Y35A, TbCSV-[Y35] DNA-A; Y35 $\beta$, TbCSV-[Y35] DNA $\beta$; and Y2 $\beta$, TbCSV-[Y2] DNA $\beta$.

b dpi, days postinoculation; wpi, weeks postinoculation.

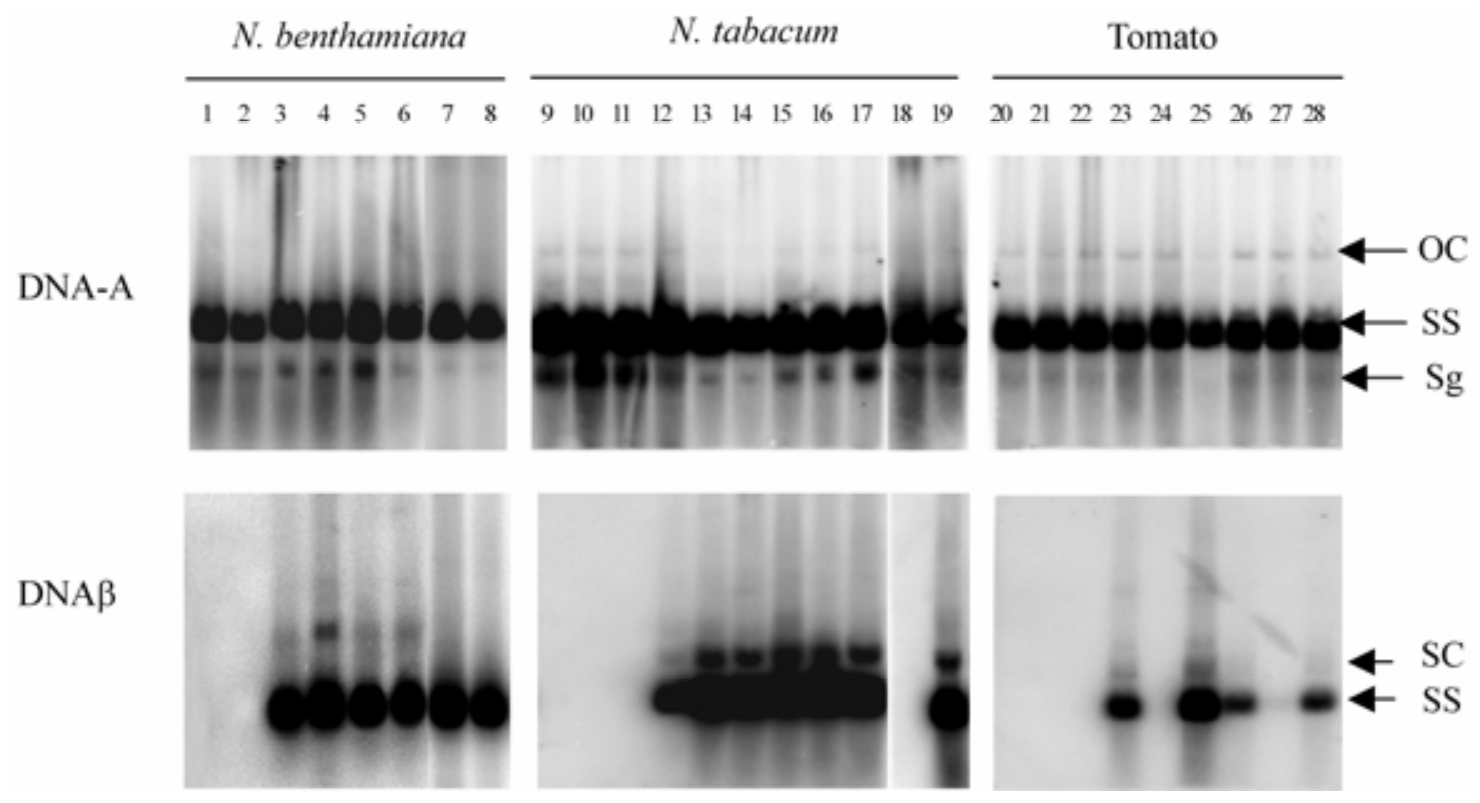

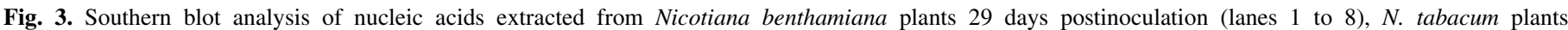

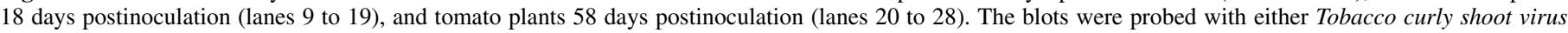

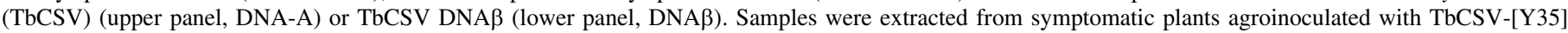

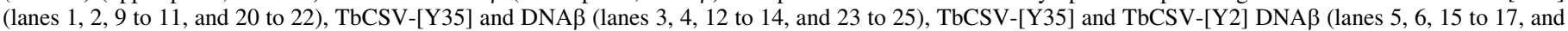

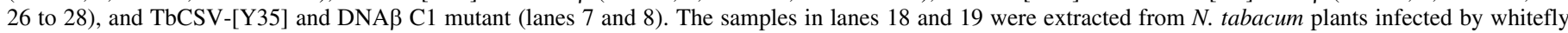

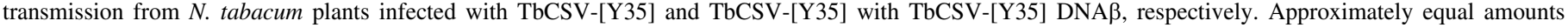

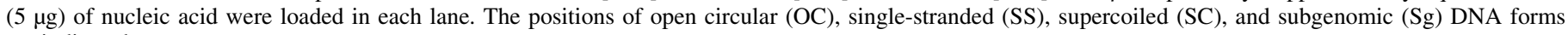
are indicated. 
toms. For TbCSV in tobacco, however, the presence of DNA $\beta$ acts to marginally intensify symptoms. Similar to AYVV, TbCSV induces an upward leaf curl in $N$. benthamiana in the absence of DNA $\beta$ and a downward leaf curl in the presence of the satellite (25). In contrast, CLCuMV in this host induces qualitatively similar symptoms in the presence and absence of the satellite $(4,5)$. These findings demonstrate that the effects of DNA $\beta$ are hostdependent and provide strong evidence suggesting that, in addition to the viruses, DNA $\beta$ satellites are also host-adapted.

In contrast to the previously characterized begomovirus-DNA $\beta$ complexes, the interaction of TbCSV with its DNA $\beta$ is a little more relaxed. TbCSV is capable of inducing severe disease in its major host, tobacco, in the absence of DNA $\beta$. This conclusion is supported by the field data, indicating that only a small proportion of TbCSV isolates in tobacco have the satellite. In tomato, the situation is even more extreme. In a significant number of plants inoculated with clones of TbCSV and DNA $\beta$, only replication of the helper virus could be detected, suggesting that there is little selection pressure for the maintenance of the satellite in this host. TbCSV may thus be an evolutionary intermediate between the truly monopartite begomoviruses (such as TYLCV and ToLCV) and those that require the satellite DNA $\beta$ (such as AYVV, CLCuMV, and TYLCCNV).

A further uncertainty is whether TbCSV is a monopartite begomovirus gaining a DNA $\beta$ satellite (the expansion hypothesis) or a DNA $\beta$-associated virus losing this component (the constriction hypothesis). The results presented here would appear to favor the constriction hypothesis, with TbCSV moving toward a monopartite habit, at least in solanaceous hosts. Were the expansion hypothesis correct we would expect to find the source of TbCSV DNA $\beta$ (i.e., another begomovirus associated with TbCSV DNA $\beta$ ) in the field. However, our efforts to identify TbCSV DNA $\beta$ associated with any other begomovirus species, involving the screening of hundreds of samples collected from diverse plant species (including tobacco, tomato, squash, papaya, A. conyzoides, Malvastrum coromandelianum, Siegesbeckia orientalis, and Euphorbia pulcherrima), in Southern China have been unsuccessful (34; X. Zhou and Y. Xie, unpublished data). The continued presence of TbCSV DNA $\beta$, in a small number of isolates, may be explained by a requirement for the satellite in an alternate host, which is no longer required as a reservoir for maintenance of the virus (due to large-scale cultivation of solanaceous crops) but still

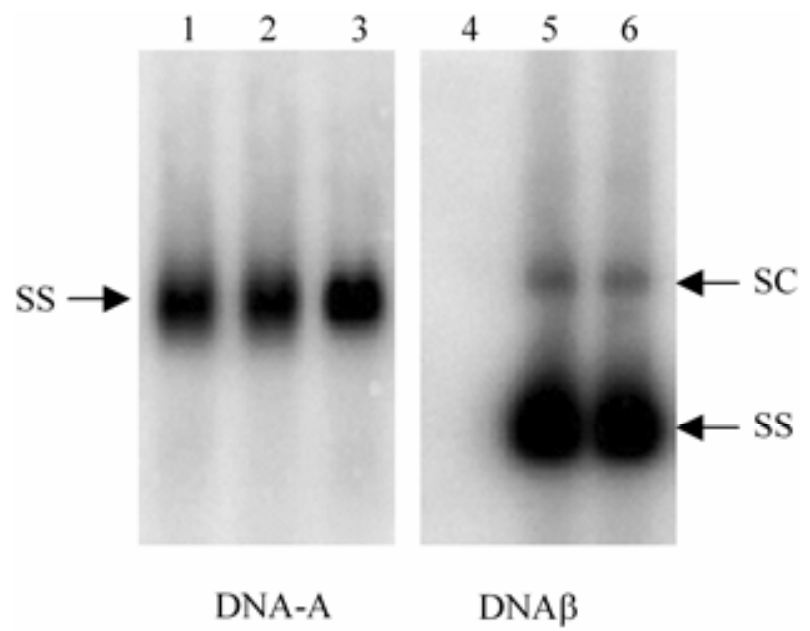

Fig. 4. Southern blot analysis of nucleic acids extracted from infected Nicotiana benthamiana plants agroinoculated with Tobacco curly shoot virus (TbCSV)[Y1] (lanes 1 and 4), TbCSV-[Y1] and TbCSV-[Y2] DNA $\beta$ (lanes 2 and 5), or TbCSV-[Y1] and TbCSV-[Y35] DNA $\beta$ (lanes 3 and 6) at 22 days postinoculation. The blots were probed either for TbCSV-[Y1] (lanes 1 to 3, DNA-A) or for TbCSV DNA $\beta$ (lanes 4 to 6 , DNA $\beta$ ). Approximately equal amounts $(5 \mu \mathrm{g})$ of nucleic acid were loaded in each lane. The positions of single-stranded (SS) and supercoiled (SC) DNA forms are indicated. plays a minor part in the epidemiology of the virus. TbCSV may thus follow in the footsteps of ToLCV, which has a nonfunctional, vestigial DNA $\beta$ satellite and probably represents a begomovirus that has dispensed with the need for this molecule $(1,8,25)$. A definitive answer to the expansion/constriction question will have to await field screening results over the next few years to determine the trend of DNA $\beta$ associating with TbCSV. An interesting parallel here is with Tomato yellow leaf curl Thailand virus (TYLCTHV). TYLCTHV is a bipartite begomovirus that does not have an absolute requirement for its DNA-B component (23). It may thus represent a virus that is dispensing with the need for a DNA-B component (22). An entirely different process to that occurring with TbCSV has been reported from the Indian subcontinent. For cotton leaf curl disease (CLCuD), it appears that the DNA $\beta$ associated with the disease (CLCuD DNA $\beta$ ) is recruiting new helper begomoviruses into the complex. A major difference here is that CLCuD DNA $\beta$ is essential for symptom induction by the helper viruses in cotton, at least six of which have been identified to date $(14,18)$.

It is interesting to note that all truly monopartite begomoviruses known at this time were isolated from tomato $(9,13,15,21)$. This suggests that tomato is a permissive host in which the requirements for the functions provided by DNA $\beta$ or DNA-B are not strictly required and that this host may be driving the evolution of a distinct subclass of begomoviruses: the monopartite begomoviruses. The begomoviruses in question, ToLCV (a major problem to tomato cultivation in northern Australia), Tomato leaf curl Philippines virus (a major limitation to crop production in the Philippines), and the Mediterranean viruses TYLCV and Tomato yellow leaf curl Sardinia virus (both important pathogens of tomato in the Mediterranean region, of which TYLCV has recently been introduced into the New World), are all viruses native to the Old World that have adapted to the introduced, New World crop tomato. No native monopartite begomoviruses are known in the New World, suggesting that the ability to dispense with the functions of DNA-B is a feature of Old World begomoviruses; many tomato-infecting begomoviruses are reported from the New World and all have a DNA-B component.

The evolutionary origin of DNA $\beta$ remains unclear. It has been suggested that DNA $\beta$ may have originated from another group of, as yet unidentified, single-stranded DNA viruses (19). This suggestion was based on the presence in DNA $\beta$ of an adenine-rich (A-rich) region of sequence. A similar A-rich region is found in the unrelated satellite-like molecule DNA 1 that is frequently associated with begomovirus-DNA $\beta$ complexes $(2,20,27,30)$. DNA 1 components are evolutionarily related to nanoviruses. However, no homolog of the DNA $\beta$ component has been reported for nanoviruses and it is thus unlikely that this component originates from this family of viruses.

\section{ACKNOWLEDGMENTS}

We thank R. Briddon (National Institute of Biotechnology and Genetic Engineering, Faisalabad, Pakistan) for critically reading the manuscript. This work was supported by National Outstanding Youth Foundation (grant 30125032) and the National Natural Science Foundation of China (grants 30400015 and 30270062).

\section{LITERATURE CITED}

1. Briddon, R. W., Bull, S. E., Amin, I., Idris, A. M., Mansoor, S., Bedford, I. D., Dhawan, P., Rishi, N., Siwatch, S. S., Abdel-Salam, A. M., Brown, J. K., Zafar, Y., and Markham, P. G. 2003. Diversity of DNA $\beta$, a satellite molecule associated with some monopartite begomoviruses. Virology 312:106-121.

2. Briddon, R. W., Bull, S. E., Amin, I., Mansoor, S., Bedford, I. D., Rishi, N., Siwatch, S. S., Zafar, Y., Abdel-Salam, A. M., and Markham, P. G. 2004. Diversity of DNA 1: A satellite-like molecule associated with monopartite begomovirus-DNA $\beta$ complexes. Virology 324: $462-474$. 
3. Briddon, R. W., Bull, S. E., Mansoor, S., Amin, I., and Markham, P. G. 2002. Universal primers for the PCR-mediated amplification of DNA $\beta$ A molecule associated with some monopartite begomoviruses. Mol. Biotechnol. 20:315-318.

4. Briddon, R. W., Mansoor, S., Bedford, I. D., Pinner, M. S., and Markham, P. G. 2000. Clones of cotton leaf curl geminivirus induce symptoms atypical of cotton leaf curl disease. Virus Genes 20:19-26.

5. Briddon, R. W., Mansoor, S., Bedford, I. D., Pinner, M. S., Saunders, K., Stanley, J., Zafar, Y., Malik, K. A., and Markham, P. G. 2001. Identification of DNA components required for induction of cotton leaf curl disease. Virology 285:234-243.

6. Bull, S. E., Tsai, W. S., Briddon, R. W., Markham, P. G., Stanley, J., and Green, S. K. 2004. Diversity of begomovirus DNA $\beta$ satellites of nonmalvaceous plants in east and south east Asia. Arch. Virol. 149:11931200.

7. Cui, X. F., Tao, X. R., Xie, Y., Fauquet, C. M., and Zhou, X. P. 2004. A DNA $\beta$ associated with Tomato yellow leaf curl China virus is required for symptom induction in hosts. J. Virol. 78:13966-13974.

8. Dry, I. B., Krake, L. R., Rigden, J. E., and Rezaian, M. A. 1997. A novel subviral agent associated with a geminivirus: The first report of a DNA satellite. Proc. Natl. Acad. Sci. USA 94:7088-7093.

9. Dry, I. B., Rigden, J. E., Krake, L. R., Mullineaux, P. M., and Rezaian, M. A. 1993. Nucleotide sequence and genome organization of tomato leaf curl geminivirus. J. Gen. Virol. 74:147-151.

10. Gafni, Y., and Epel, B. L. 2002. The role of host and viral proteins in intra- and inter-cellular trafficking of geminiviruses. Physiol. Mol. Plant Pathol. 60:231-241.

11. Hanley-Bowdoin, L., Settlage, S. B., Orozco, B. M., Nagar, S., and Robertson, D. 1999. Geminiviruses: Models for plant DNA replication, transcription, and cell cycle regulation. Crit. Rev. Plant Sci. 18:71-106.

12. Jose, J., and Usha, R. 2003. Bhendi yellow vein mosaic disease in India is caused by association of a DNA $\beta$ satellite with a begomovirus. Virology 305:310-317.

13. Kheyr-pour, A., Bendahmane, M., Matzeit, V., Accotto, G. P., Crespi, S., and Gronenborn, B. 1991. Tomato yellow leaf curl virus from Sardinia is a whitefly-transmitted monopartite geminivirus. Nucleic Acids Res. 19:6763-6769.

14. Kirthi, N., Priyadarshini, C. G. P., Sharma, P., Maiya, S. P., Hemalatha, V., Sivaraman, P., Dhawan, P., Rishi, N., and Savithri, H. S. 2004. Genetic variability of begomoviruses associated with cotton leaf curl disease originating from India. Arch. Virol. 149:2047-2057.

15. Kon, T., Dolores, L. M., Murayama, A., Bajet, N. B., Hase, S., Takahashi, H., and Ikegami, M. 2002. Genome organization of an infectious clone of Tomato leaf curl virus (Philippines), a new monopartite begomovirus. J. Phytopathol. 150:587-591.

16. Lazarowitz, S. G. 1992. Geminiviruses-Genome structure and gene function. Crit. Rev. Plant Sci. 11:327-349.

17. Li, Z. H., Zhou, X. P., Zhang, X., and Xie, Y. 2004. Molecular characterization of tomato-infecting begomoviruses in Yunnan, China. Arch. Virol. 149:1721-1732.

18. Mansoor, S., Briddon, R. W., Bull, S. E., Bedford, I. D., Bashir, A., Hussain, M., Saeed, M., Zafar, Y., Malik, K. A., Fauquet, C., and Markham, P. G. 2003. Cotton leaf curl disease is associated with multiple monopartite begomoviruses supported by single DNA $\beta$. Arch. Virol. 148:1969-1986.

19. Mansoor, S., Briddon, R. W., Zafar, Y., and Stanley, J. 2003. Geminivirus disease complexes: An emerging threat. Trends Plant Sci. 8:128-134.
20. Mansoor, S., Khan, S. H., Bashir, A., Saeed, M., Zafar, Y., Malik, K. A., Briddon, R. W., Stanley, J., and Markham, P. G. 1999. Identification of a novel circular single-stranded DNA associated with cotton leaf curl disease in Pakistan. Virology 259:190-199.

21. Navot, N., Pichersky, E., Zeidan, M., Zamir, D., and Czosnek, H. 1991. Tomato yellow leaf curl virus - A whitefly-transmitted geminivirus with a single genomic component. Virology 185:151-161.

22. Rochester, D. E., DePaulo, J. J., Fauquet, C. M., and Beachy, R. N. 1994 Complete nucleotide sequence of the geminivirus tomato yellow leaf curl virus, Thailand isolate. J. Gen. Virol. 75:477-485.

23. Rochester, D. E., Kositratana, W., and Beachy, R. N. 1990. Systemic movement and symptom production following agroinoculation with a single DNA of tomato yellow leaf curl geminivirus (Thailand). Virology 178:520-526.

24. Rojas, M. R., Jiang, H., Salati, R., Xoconostle-Cazares, B., Sudarshana, M. R., Lucas, W. J., and Gilbertson, R. L. 2001. Functional analysis of proteins involved in movement of the monopartite begomovirus, Tomato yellow leaf curl virus. Virology 291:110-125.

25. Saunders, K., Bedford, I. D., Briddon, R. W., Markham, P. G., Wong, S. M., and Stanley, J. 2000. A unique virus complex causes Ageratum yellow vein disease. Proc. Natl. Acad. Sci. USA 97:6890-6895.

26. Saunders, K., Bedford, I. D., and Stanley, J. 2001. Pathogenicity of a natural recombinant associated with Ageratum yellow vein disease: Implications for geminivirus evolution and disease etiology. Virology 282:38-47.

27. Saunders, K., Bedford, I. D., and Stanley, J. 2002. Adaptation from whitefly to leafhopper transmission of an autonomously-replicating nanoviruslike DNA component associated with Ageratum yellow vein disease. J. Gen. Virol. 83:909-915.

28. Saunders, K., Bedford, I. D., Yahara, T., and Stanley, J. 2003. The earliest recorded plant virus disease. Nature 422:831.

29. Saunders, K., Norman, A., Gucciardo, S., and Stanley, J. 2004. The DNA $\beta$ satellite component associated with ageratum yellow vein disease encodes an essential pathogenicity protein ( $\beta C 1)$. Virology 324:37-47.

30. Saunders, K., and Stanley, J. 1999. A nanovirus-like DNA component associated with yellow vein disease of Ageratum conyzoides: Evidence for interfamilial recombination between plant DNA viruses. Virology 255:142-152.

31. Stanley, J., Bisaro, D. M., Briddon, R. W., Brown, J. K., Fauquet, C. M., Harrison, B. D., Rybicki, E. P., and Stenger, D. C. 2004. Geminiviridae. Pages 301-326 in: Virus Taxonomy. VIIIth Report of the International Committee on Taxonomy of Viruses. C. M. Fauquet, M. A. Mayo, J. Maniloff, U. Desselberger, and L. A. Ball, eds. Elsevier/Academic Press, London.

32. van Engelen, F. A., Molthoff, J. W., Conner, A. J., Nap, J. P., Pereira, A., and Stiekema, W. J. 1995. pBINPLUS: An improved plant transformation vector based on pBIN19. Transgenic Res. 4:288-290.

33. Xie, Y., Zhou, X. P., Zhang, Z. K., and Qi, Y. J. 2002. Tobacco curly shoot virus isolated in Yunnan is a distinct species of begomovirus. Chin. Sci. Bull. 47:197-200.

34. Zhou, X. P., Xie, Y., Tao, X. R., Zhang, Z. K., Li, Z. H., and Fauquet, C. M. 2003. Characterization of DNA $\beta$ associated with begomoviruses in China and evidence for co-evolution with their cognate viral DNA-A. J. Gen. Virol. 84:237-247.

35. Zhou, X. P., Xie, Y., Zhang, Z. K., Qi, Y. J., and Wu, J. J. 2001. Molecular characterization of a novel defective DNA isolated from tobacco tissues infected with tobacco leaf curl virus. Acta Virol. 45:45-50. 